\title{
Dear Olive Tree
}

\author{
ANNETTE ARLANDER [D
}

\section{ब나}

Open Library of Humanities

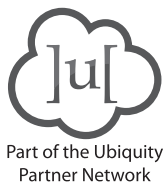

\section{ABSTRACT}

This video article consists of the video Dear Olive Tree $(19 \mathrm{~min}$ ) recorded in La Foia d'Ulldecona on 19 December 2019 with olive tree no. 968, three letters written to the tree and some reflections.

CORRESPONDING AUTHOR:

\section{Annette Arlander}

University of the Arts Helsinki, FI annette.arlander@uniarts.fi

KEYWORDS

olive tree; letter; performing writing

TO CITE THIS ARTICLE: Arlander, A. 2021. Dear Olive Tree. Journal of Embodied Research, 4(2): 5 (19:40). DOI: https://doi.org/10.16995/jer.70 
VIDEO ARTICLE

Available to view here: https://doi.org/10.16995/jer.70.

Available for download here: https://doi.org/10.16995/jer.70.s1.

\section{STILLS FROM THE VIDEO ARTICLE}
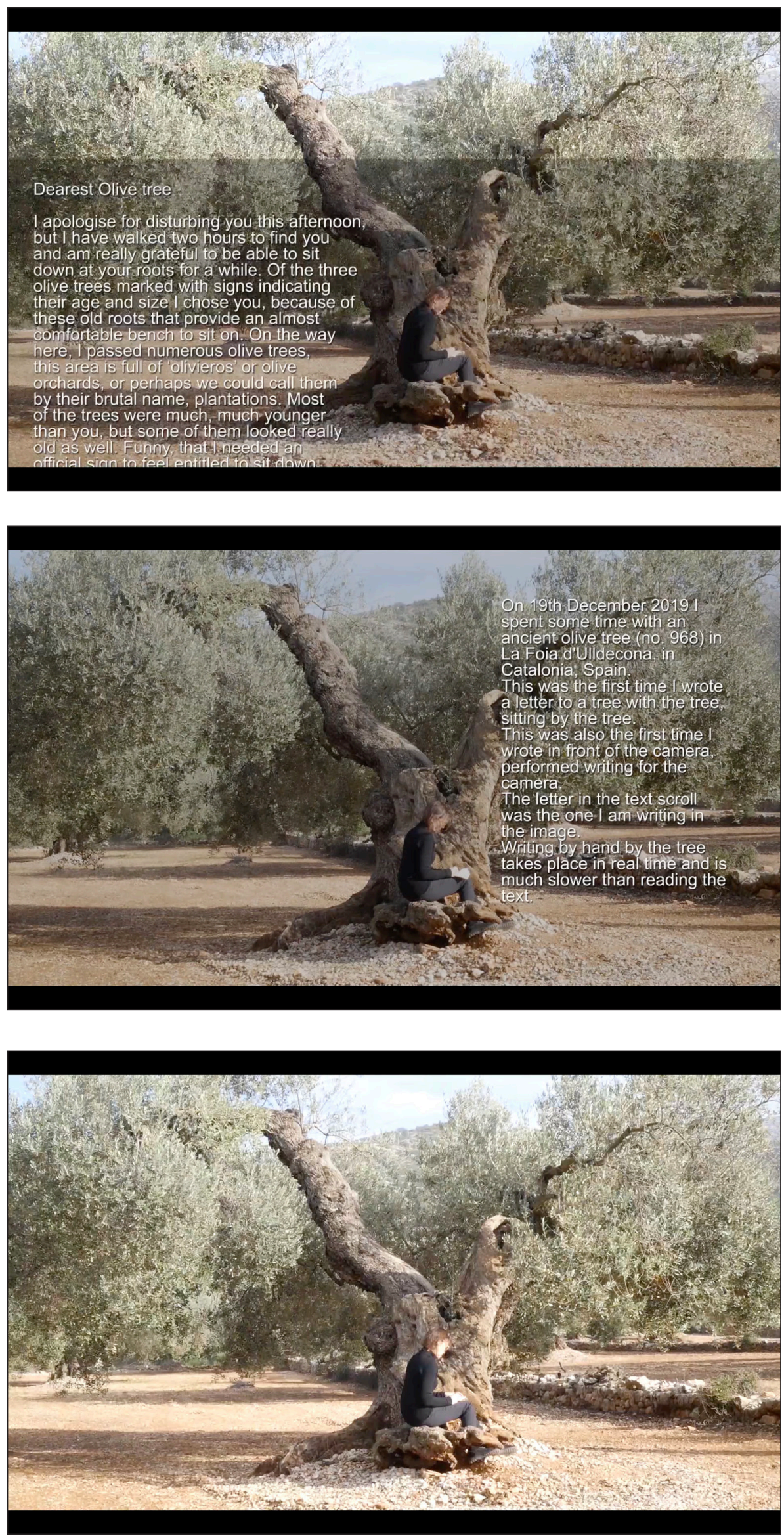


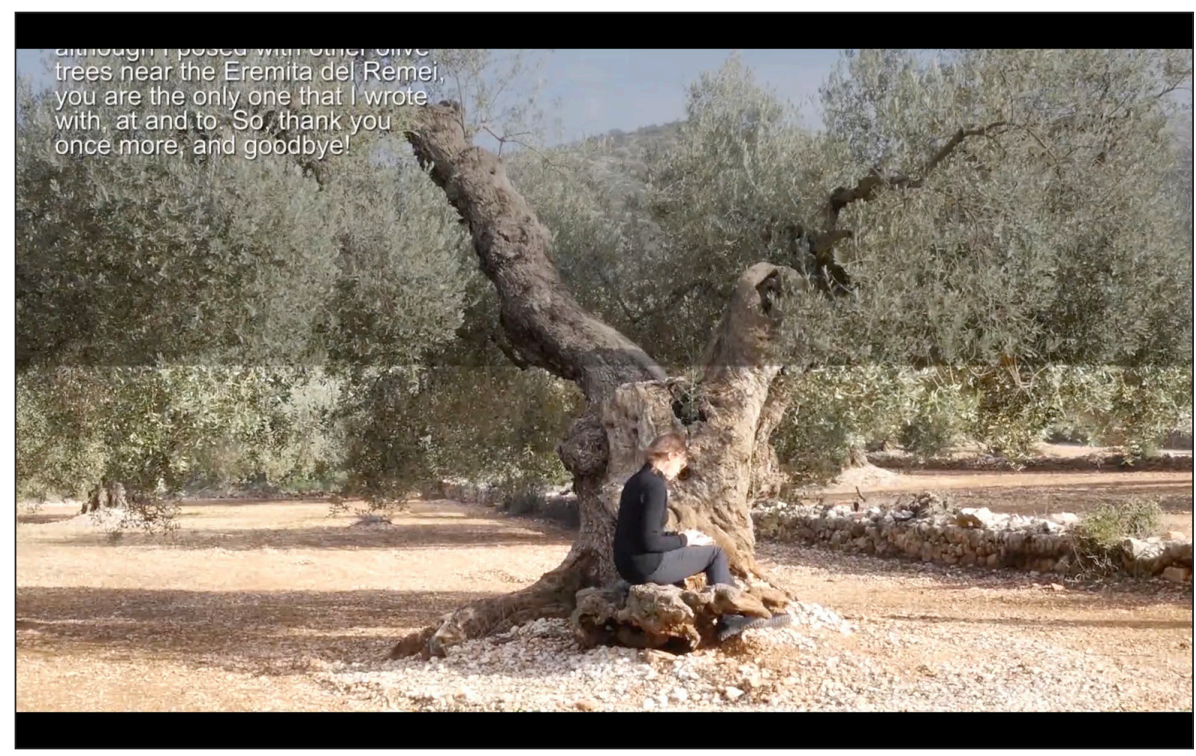

\section{VIDEO ARTICLE TRANSCRIPT}

[Note: This is a transcript of a video article. Individual elements from the transcript, such as metadata and reference lists, may appear more than once in the document, in order to be properly read and accessed by automated systems. The transcript can be used as a placeholder or reference when it is not possible to embed the actual video, which can be found by following the DOI.]

[00:10]

\section{Dear Olive Tree}

\section{Dearest Olive tree}

I apologise for disturbing you this afternoon, but I have walked two hours to find you and am really grateful to be able to sit down at your roots for a while. Of the three olive trees marked with signs indicating their age and size I chose you, because of these old roots that provide an almost comfortable bench to sit on. On the way here, I passed numerous olive trees, this area is full of 'olivieros' or olive orchards, or perhaps we could call them by their brutal name, plantations. Most of the trees were much, much younger than you, but some of them looked really old as well. Funny, that I needed an official sign to feel entitled to sit down, as if you were on duty, serving the tourist industry now, in your old age. The officially oldest olive tree in (Catalonia), Spain, Europe, and perhaps the world, grows only a few kilometres away from here, on a private estate called L'Arion, that has made a business of allowing (only) guided tours to visit the tree. I am really happy and proud to have found you, with a little help from a city clerk serving as a make-do tourist officer, since the tourist office in Ulldecona is closed. He made me a map how to get here, based on a note on the website. This little grove is called La Foia d'Ulldecona and is clearly marked by bright green signboards. Right now, there is no-one else here but me - and you, of course, all of you. Some of the trees around you look much younger, and only three are marked with information boards. They are all more than 900 years old. They say that many of you, old olive trees, have been cut down and replaced by other types of olive trees that yield larger harvests of olives. But some clever managers have realized that they can make a profit by selling olive oil made from these old, old ones, like you. I am rather old myself, although never near your venerable age, even transposed to human terms, but, in any case, I can identify with the feeling of getting older and not being as productive and quick to learn new things as younger people. So, I sympathize with the idea of finding value in the products of elders, more slowly made, but perhaps special in their (flavour, in their) own way. - The sun is surprisingly warm even though it is winter solstice time, soon. When the clouds cover it, the air is chilly, but when it is shining it almost burns like in summertime. I wonder where you get the water you need to keep your leaves up and working? I guess it rains sometimes, and then you simply try to economize with it. The soil around you is bare, almost rocks and sand only, obviously prepared by humans. Perhaps it is easier to pick the olives, and you have then no competition. I noticed some abandoned groves where the olive trees were almost overgrown 
by shrubs. It seems like the collaboration between olives and humans has such long traditions, that some kind of balance suitable for both has been formed. I hope that this intrusion of mine does not disturb that balance, and why would it? In your nine hundred and something years some twenty minutes does not count as much. - I nevertheless thank you for allowing me to sit here and make these notes. And I wish you all the best for the next hundred years, and more. Goodbye for now!

On 19th December 2019 I spent some time with an ancient olive tree (no. 968) in La Foia d'Ulldecona, in Catalonia, Spain.

This was the first time I wrote a letter to a tree with the tree, sitting by the tree.

This was also the first time I wrote in front of the camera, performed writing for the camera.

The letter in the text scroll is the one I am writing in the image.

Writing by hand by the tree takes place in real time and is much slower than reading the text.

[07:00]

Dearest Olive Tree,

After our brief encounter on Thursday I have met some other ancient olive trees, and also learned that it is not your age that determines the number on the sign next to you (how stupid of me to think of that) but the order you have been identified, however that was determined. I am sorry for this mistake, which is due to my carelessness in reading the signs. I was so attuned to the idea of ages around 1000 years because of the title colivieros millenarios', which does not mean millennials as the term is used in popular culture to refer to young people born in the eighties or even the nineties, but to thousand years of age, at least that is what I thought. But it seems that the title is more of an image trick, and the defining characteristics are size and height, size both in terms of width of the trunk and width of the crown. These are all indicators of age, of course, but nothing as definitive as exact birth date. There are some trees that have a clear date when they are planted, and if the historical information is accurate, that gives a clear idea of age. But, as far as I understand, you are not one of them. But never mind, exact age is nothing we should care too much about. Age is a number, as they say, and health as well as vitality is what counts. I am sometimes irritated when health apps constructed to create facts about human fitness say "excellent for your age". What does that mean? Excellent statistically compared with other people of my age? But that says nothing, really, if most of the population is in a really poor condition. If you compare with weight, it is easy to understand. If the whole population is obese, a person who is seriously overweight could be called "normal" or "fit for your age", or age group... But, anyway. The average is a usual way of determining the normal, I guess. - So, what about olive trees? Is it "normal" to live to a ripe old age of 1000 years, or is it simply a modern fad? Or, on the contrary, was it perhaps more common in earlier times to respect and care for ancient trees, while contemporary agriculture prefers productive mutations and quick profit, fast-growing, reliable, all alike? - Sorry for being obsessed by age, or so it seems. I really think of our brief moments together as an exercise in enjoying the company of trees. I am still astonished how little I managed to write in twenty minutes, perhaps because I was writing by hand, or perhaps because I had calmed down a little, influenced by your solid presence. I am already feeling more serene simply by thinking of your wrinkled bark. I hope you are enjoying your time in La Foia d'Ulldecona, and that you are given time to rest between disturbing visits by humans, like me. Of course, I like to think that you enjoy the attention of human visitors, but strictly speaking, why would you? I guess you have plenty of company with the other ancient olive trees (and some younger ones, too) growing nearby. Anyway, I wish you all the best, and send you my greetings from the busy life of a human city... Take care!

The second letter I wrote the following day in the nearby Alcanar.

In later experiments I did not write to trees afterwards, I only addressed the tree when being next to the tree.

Writing next to the tree becomes a way of addressing the tree in an I-You relationship.

Performing writing for camera becomes a session of automatic writing.

Writing to the tree next to the tree becomes a practice of performing with the tree. 
In later experiments I read and recorded the text written during the performance and added it as a voice-over to the video.

\section{[13:20]}

Dearest Olive Tree,

This is a last note to you from Vinaroz, a town not too far from your home. I am on my way, waiting for the train, and just wanted to send you one more note to say thank you, and good luck. You might be happy to know that I visited the museum grove at L'Arion with your very, very ancient relative, La Farga de L'Arion, and was of course impressed by its size and its age (1704 years!). They seem to know that because of the planting date, 314 a.d. But there was never any kind of possibility for intimacy or even a personal contact. Of all the monumental olive trees in the region, you remain the foremost representative to me. I realize it would be very dangerous and tiring for you and your kind if humans would keep sitting on you or climbing up in you and so on, like I did with some of you the other day. I fully understand the behavioural restrictions in the museum grove. I am nevertheless happy to have had the chance to make more concrete acquaintance with you, and with all the time in the world that we wanted, rather than a hurried walk from one olive tree to the next. Although the guide spoke in Catalan, I understood some details that he clarified in some sort of English, like the fact that all the huge old olive trees, or most of them, are of one specific species or type, namely Olea Farga, with particular oblong olives. I am more or less sure that you are one of these Farga trees as well, although I am not $100 \%$ certain. Rest assured, however, that I will remember you with sympathy and gratitude, and even though the small branch I took as a souvenir of you remained in a glass of water in the bathroom in my hotel room in Alcanar, the images and video clips will keep your memory fresh in my mind. And although I posed with other olive trees near the Eremita del Remei, you are the only one that I wrote with, at and to. So, thank you once more, and goodbye!

The third and last letter I wrote in Vinaroz, when leaving the area.

This experiment in letter writing took place at the very end of a three year-artistic research project "Performing with Plants".

It became the starting point for a whole series of letters to trees.

This moment with an ancient olive tree (no. 968) turned out to be one of the beginnings to the project "Meetings with Remarkable and Unremarkable Trees".

Arlander 2019

Dear Olive Tree

performed, written recorded and edited by

Annette Arlander (in collaboration with the tree)

This video article consists of the video Dear Olive Tree (19 min)

recorded in La Foia d'Ulldecona on 19 December 2019

with olive tree no. 968, three letters written to the tree

and some reflections.

Keywords: olive tree, letter, performing writing

References:

"Meetings with Remarkable and Unremarkable Trees". https://annettearlander.com/current-projects/meetings-with-remarkable-and-unremarkable-trees/

"Performing with Plants".

https://annettearlander.com/current-projects/performing-with-plants/

The author declares no competing interests.

\section{COMPETING INTERESTS}

The author has no competing interests to declare. 
AUTHOR AFFILIATIONS

Annette Arlander (1D) orcid.org/0000-0002-9752-8850

University of the Arts Helsinki, FI

\section{REFERENCES}

"Meetings with Remarkable and Unremarkable Trees". https://annettearlander.com/current-projects/ meetings-with-remarkable-and-unremarkable-trees/.

"Performing with Plants". https://annettearlander.com/current-projects/performing-with-plants/.
Journal of Embodied

Research

DOI: $10.16995 /$ jer.70

TO CITE THIS ARTICLE: Arlander, A. 2021. Dear Olive Tree. Journal of Embodied Research, 4(2): 5 (19:40). DOI: https://doi.org/10.16995/jer.70

Submitted: 25 October 2020

Accepted: 24 July 2021

Published: 11 October 2021

COPYRIGHT:

(c) 2021 The Author(s). This is an open-access article distributed under the terms of the Attribution-NonCommercialNoDerivatives 4.0 International License (CC BY-NC-ND 4.0), which permits unrestricted use, distribution, and reproduction in any medium, provided the original author and source are credited. See https:// creativecommons.org/licenses/ by-nc-nd/4.0/.

Journal of Embodied Research is a peer-reviewed open access journal published by Open Library of Humanities. 